\title{
PROFISSIONAL ATUÁRIO E A RELAÇÃO COM O AQUECIMENTO DA CONSTRUÇÃO
} CIVIL

Cristiane Martins, Irene Caires da Silva, Marlon Kipson, Tais Marina Guimarães Oliveira, Thais Laressa Galvão Santos, Thais Rubia Ferreira Lepre, Thaynara Alana Galvão Santos

Universidade do Oeste Paulista - UNOESTE. Curso de Ciências Contábeis, Presidente Prudente - SP. E-mail: irene@unoeste.br

\section{RESUMO}

Este artigo apresenta o perfil do contador atuário, identificando uma das suas principais áreas de atuação a de seguros, e suas oportunidades no aquecimento da construção civil relacionados com a Copa do Mundo 2014, visto uma maior quantidade de pessoas e equipamentos. O mercado tem se expandido pela necessidade que as pessoas no geral, buscam uma segurança e garantia dos seus bens, e diante disso, esta pesquisa tem por objetivo identificar as oportunidades que as construções civis no Brasil podem trazer ao Profissional atuário. E para tanto optou-se por uma abordagem qualitativa tendo a pesquisa bibliográfica e a documental como instrumento de coleta de dados. Assim, é momento de oportunidade para o profissional, que apesar da sua importância e da procura ainda é pouco conhecido e se esconde atrás das seguradoras, é sua especialidade a matemática superior de modo geral, cálculos estatísticos de riscos e eventos.

Palavras-chave: Oportunidade, Atuação, Mercado, Expansão, Copa do Mundo.

\section{ACTUARY PROFESSIONAL RELATIONSHIP WITH THE HEAT OF CONSTRUCTION}

\begin{abstract}
This article presents an actuary accountant profile, identifying one of its main areas of focus to insurance, and opportunities for heating the building related to the World Cup in 2014, as a greater amount of people and equipment. The market has expanded the need that people in general are seeking a safety and security of their property, and before, this research aims to identify the opportunities that civilian buildings in Brazil can bring to professional actuary. And so we chose a qualitative approach with the literature and the documentary as a tool for data collection. Thus, it is time of opportunity for the professional who despite their importance and demand is still little known and hides behind the insurers, their specialty is the higher mathematics in general, statistical calculations of risks and events.
\end{abstract}

Keywords: Opportunity, Performance, Market Expansion, World Cup. 


\section{INTRODUÇÃO}

A contabilidade é a ciência que registra, resume e interpreta fenômenos financeiros, patrimoniais e econômicos da empresa e pessoas. Originou-se da necessidade de controlar os bens nos primórdios da civilização. Conforme a evolução e necessidades da sociedade, o cenário da contabilidade tem sido ampliado e esta em constante alteração, o que exige do contador antes visto como guarda-livros, um conhecimento geral para suas tomadas de decisão, pois são os intermediários dos relacionamentos entre empresas e sociedade.

Entretanto com o surgimento de novas técnicas e recursos gerenciais, o contador não se limitou e expandiu sua área de atuação, entre elas o contador atuário.

O profissional atuário surgiu no século XIX no Brasil, mas em meados da década de 60 passou a ser reconhecido. Mesmo sendo um mercado de grande expansão, o profissional é pouco conhecido e considerado uma das profissões do futuro. É especialista em problemas secundários, Previdência Social e Privada, com atuação principal nas áreas de avaliação de riscos, cálculos de prêmios de seguros, pecúlios, planos de aposentadoria e pensão.

Mais do que nunca precisa desse profissional no país, o Brasil esta em um momento de crescimento e oportunidades devido às obras da Copa do Mundo 2014, com isso a Construção Civil que antes já vinha em ritmo acelerado, se encontra em um patamar mais elevado.

Diante disso, este trabalho pretende responder a seguinte problemática: quais são as oportunidades que o aquecimento da Construção Civil no Brasil, pode trazer ao profissional atuário? O Aquecimento da Construção Civil no Brasil tem favorecido o segmento de seguros, a procura não é apenas seguro de obras, é também seguros de vida e de equipamentos. Visto que, atualmente há um número maior de pessoas trabalhando e equipamentos sendo utilizados nas construções, e a Copa do Mundo de 2014 é um grande investimento em infraestrutura, onde o profissional atuário tem a oportunidade de se destacar junto à tecnologia, proporcionando tranquilidade e segurança tanto para o segurado, quanto para o segurador, e esta é a justificativa para existência desta pesquisa que pretende mostrar as oportunidades que o aquecimento da Construção Civil traz ao atuário.

A pesquisa tem por objetivo identificar as oportunidades que as construções civis no Brasil podem trazer ao Profissional atuário. Desta forma o presente artigo ira esclarecer o perfil do contador atuário. 
O PROFISSIONAL ATUÁRIO E A OPORTUNIDADE NA CONSTRUÇÃO CIVIL

Atualmente a incerteza que caracteriza a vida das pessoas como frequentes riscos imprevisíveis e inevitáveis, vem aumentando o interesse em proteger o patrimônio, a saúde e a vida.

De acordo com os estudos realizados por Souza (2002, p.142).

ciências atuariais é o ramo do conhecimento que lida com matemática de seguro, incluindo probabilidades, usada para garantir que os riscos sejam cuidadosamente avaliados, os prêmios sejam estabelecidos adequadamente pelos classificadores de riscos e a provisão para os pagamentos futuros de benefícios seja adequada. (SOUZA, 2002,p.142).

As ciências atuariais é uma ciência que analisa os riscos, ou seja, condições de perdas possíveis nas empresas seguradoras e previdenciárias. Ela utiliza conhecimentos nas áreas da matemática, estatística para avaliar os riscos e fixar os prêmios que são os preços pagos pelos segurados além de obter um planejamento de curto, médio e longo prazo.

A ciência atuarial hoje é pouco conhecida pelo público, apesar de que na antiga Roma o profissional atuário era o escrivão encarregado de fazer discursos pronunciados no senado, o responsável por escrever os atos do governo; copista, secretário, notário, entre outros. E apesar de não possuir noção de probabilidade os romanos naquela época sabiam distinguir claramente renda vitalícia, durante a vida, da renda perpétua, válida para sempre.

O primeiro Congresso Internacional de Atuária ocorreu em Bruxelas no final do século XIX já no Brasil o primeiro curso universitário de Ciências Atuariais surgiu na década de 1940 com formação específica obrigatória a todos os atuários (SOUZA, 2002).

O Instituto Brasileiro de Atuária (IBA) foi fundado em 1944 por iniciativa de pesquisadores e matemáticos interessados em expandir o campo de estudos e trabalhos de natureza atuarial (IBA, 2010). É o órgão representante dos atuários e seu objetivo é o desenvolvimento e o aperfeiçoamento da Ciência e da tecnologia em todo seu aspecto e técnicas de aplicação.

O Atuário é um técnico cujo instrumento de trabalho é a estatística, e executa cálculos das operações financeiras, ajusta as operações realizadas em relação as provisões técnicas, à venda dos seguros e sua manutenção. (STANDERSKI E KRAVEC, 1979. p. 109)

No Brasil o profissional atuário ainda não foi devidamente apresentado a sociedade, existem poucas instituições de ensino que oferecem o curso e que são reconhecidos no país. 0 curso de Ciências Atuariais tem duração de quatro anos. Após o termino do curso o Atuário 
poderá trabalhar em Órgãos de fiscalização, Instituições financeiras, Seguradoras, Resseguradoras, Fundo de pensões, Previdência social, entre outras áreas de atuação não citadas.

O atuário é o profissional capacitado e especializado para solucionar questões relativas à aplicação de seguros por meio da Ciência Atuarial utilizando ferramentas indispensáveis como a Matemática e a Probabilidade. Entre as áreas de conhecimento importantes para a formação do Atuário está a Estatística, Informática, Contabilidade, Economia, Administração e Direito.

São atribuições da profissão segundo o IBA (2010) atuar em todas as áreas de risco como calcular probabilidade de eventos, avaliar os riscos e as possibilidades de danos e perdas, determinar a tarifa dos prêmios de seguros, desenvolver planos de financiamentos, refinanciamentos, na seguradora estuda o nível de incidências como invalidez, doença, fecundidade e natalidade. Por fim o atuário pode exercer as atividades de docentes em faculdades de ensino superior.

O Profissional deve sempre estar atento às oportunidades que surgem de acordo com as necessidades da sociedade. Vale ressaltar que o contador atuário não fica para traz em termos salariais, são bem remunerados.

Atualmente no Brasil o mercado de seguros é favorável para esse profissional, pelo fato de que há um aumento constante no número de construções civis, com as obras de infraestrutura relacionadas à Copa do Mundo FIFA 2014 e aos Jogos Olímpicos de 2016 no Rio de Janeiro. Sendo assim, o setor da Construção Civil vive um dos seus melhores momentos, está no centro dos investimentos em função da Copa do Mundo, Lima et al., $(2008$, p. 25) enfatiza que a "indústria da construção civil é um importante setor da economia brasileira, de uso intensivo de mão de obra e geração de empregos", deixando claro sua importância e um crescimento nos segmentos de obras comerciais, habitacionais e outras. Diante disso, sua expansão é dada na medida em que pensa num conforto geral, ou seja, no que esta relacionada com Copa do Mundo necessita de estar atraente, considerando que esse evento meche com os corações dos brasileiros.

Antes, muito só se falava no mercado imobiliário que estava em alta e muito bem valorizado, agora com todo esse movimento outros segmentos também estão aumentando sua demanda como as indústrias de pré-moldados e calhas, empreiteiras e incorporadoras, esquadrilhas, serralherias, os engenheiros sendo mais procurado, até mesmo o curso de Engenharia Civil entra em destaque. Com isso, é necessária a garantia de que tudo ocorra conforme a rota planejada e caso ocorra atos involuntários causando prejuízos os seguros de responsabilidade civil garante o ressarcimento ao segurado. 
o seguro de responsabilidade civil garante o reembolso de indenizações que no segurado venha a ser obrigado a pagar em consequência de lesões corporais ou danos materiais, sofridas por terceiros por culpa involuntária do segurado ou de pessoas pelas quais deva responder civilmente. Danos materiais correspondem a lesão física ou destruição de um bem tangível ocorrido no dia em que sua existência ficou evidente para o reclamante, ainda que sua causa não seja conhecida. (SOUZA, 2002. p.73).

Como já dito, com a Copa do Mundo há um número maior de pessoas trabalhando, maquinas operando, obras em reforma e construção, entre outras. O que aumenta também a procura de seguros, pois os riscos se tornam maiores com trabalhadores e torcedores sujeitas a acidentes, locadoras preocupadas com o uso dos equipamentos e maquinas, aos proprietários de comércios que zelam por seu estabelecimento e tudo que estiver envolvido está sujeita à ocorrência de imprevisibilidade climática, danos, manifestações violentas, roubos.

\section{Expansões no Mercado de Seguros}

Seguro é uma forma de proteção de vida, bens (móveis e imóveis), previdência social, é uma segurança e garantia que o segurado possui o que é previsto, pelo atuarial nos seus cálculos.

seguro é um plano social que combina os riscos de muitos indivíduos dentro de um grupo. Atuarialmente prevê perdas e usa os fundos das contribuições dos membros do grupo para efetuar o pagamento de indenizações, quando são de vidas, nas condições e termos de contrato. (FIGUEIREDO, 2012. p.03)

Surgiu através do animal durante caravanas de grupos cameleiros na babilônia que atravessavam o deserto para comercializar animais da cidade vizinha. Durante o percurso havia dificuldade pelo perigo da travessia com a morte ou desaparecimento dos animais, para os cameleiros isso era grande risco, então entraram em um acordo em que cada membro do grupo que perdia um camelo teria direito de receber outro animal pago pelos demais cameleiros. De acordo com Souza (FIGUEIREDO, 2012, p. 149) "o risco está, por tanto, diretamente ligado a possibilidade de ocorrência de um evento futuro, esperado, ou não."

No Brasil o seguro chegou em 1808, à primeira empresa de seguro foi a companhia de seguros boa fé e tem por objetivo um centro de navegação para operar no seguro marítimo.

Nesta era das navegações tudo era investido no carregamento da embarcação, e quando havia tempestade os comerciantes corriam o risco de perder sua carga, então entraram em acordo de quem perdesse uma embarcação tinha garantia de construir outra, paga pelos demais navegares que participavam da mesma viagem. Mas o seguro não focalizou somente em seguros 
marítimos, houve uma ampliação do conceito e classificações que surgiram ao longo das necessidades.

Atualmente o seguro passou a ser necessário pela proteção de seus bens, sendo os mais conhecidos móveis (automóveis), imóveis, vida e equipamentos por serem os mais utilizados e essenciais para as pessoas e empresas.

A procura pelo seguro esta se ampliando com esta expansão no setor e passou a ser cada vez mais utilizada, beneficiando também a seguradora e os corretores, a importância deles no seguro é a confiança, a seguradora é uma agencia que vende seguro e o corretor é quem mais entende do seguro, é o conselheiro do segurado na hora de vender o seguro.

Segundo Funeseg (apud FIGUEREDO,2002,p.19)

segurado é a pessoa física ou jurídica economicamente interessada no bem exposto a risco e que transfere à seguradora, mediante pagamento de certa importância, o risco de um determinado evento em atingir o bem do seu interesse. Segurado é a pessoa em nome de quem faz o seguro.

O seguro é realizado através de um contrato entre o segurado e a seguradora, a apólice: documento emitido pela seguradora que formaliza a aceitação do risco e informações que contem o valor de coberturas e garantias pelo segurado. A seguradora cobra um preço chamado de premio, que segundo Santos (FIGUEIREDO,2012, p.21) "premio é a soma em dinheiro paga pelo segurado ao segurador para que este assuma a responsabilidade de um determinado risco" e em troca se compromete a pagar qualquer dano dos seus bens durante o período estimado na apólice. O risco é emitido do segurado, a seguradora formaliza o documento.

O seguro é universal e dependente da constituição de cada pais em preservar os seus bens, é comunitário por envolver os esforços de todos para minimizar as perdas de cada um, democrático porque se estende a todos e busca cada vez mais novos participantes para minimizar os riscos e diminuir as perdas, é economicamente eficaz por ter um modelo que se sustenta o longo da historia e tem comprovado o êxito contra as mais diferentes adversidade, além disso o seguro é um estimulo ao desenvolvimento da economia porque representa o reinvestimento da maior parte do capital acumulado.

Com o seguro podemos enfrentar as incertezas, realizar grandes empreendimentos com a confiança e a tranquilidade que necessitamos. 


\section{ASPECTOS METODOLÓGICOS}

Nesta Pesquisa se identifica os estudos qualitativos com aspecto de proporcionar a diversidade e flexibilidade, com projetos bem detalhados. O pesquisador esta lidando com fenômeno sobre qual já existe conhecimento acumulado por outras pesquisas realizadas, tem por objetivo uso e aperfeiçoamento de ideias, pautando seus estudos demonstrando sua realidade.

Os instrumentos de coleta de dados utilizados na realização da pesquisa de acordo com sua abordagem e levando em conta o seu objetivo geral, caracterizam ser do tipo documental e bibliográfica.

De acordo com os estudos realizados por Lakatos e Marconi (2003, p. 183)

A pesquisa bibliográfica ou de fontes secundárias, abrange toda bibliografia já tornada pública em relação ao tema de estudo, desde publicações avulsas, boletins, jornais, revistas, livros, pesquisas, monografias, teses, material cartográficos etc., até meios de comunicação orais: radio gravações em fita magnética e audiovisuais: filmes e televisão.

Compreendemos que a pesquisa bibliográfica coloca o pesquisador em contato direto com tudo o que foi exposto, pois utiliza do conhecimento de autores que possuem experiência sobre o tema abordado.

E de acordo com Fachin (2008, p.146), “a pesquisa documental corresponde a toda informação coletada, seja de forma oral, escrita ou visualizada". Sendo assim, caracteriza-se pesquisa documental toda e qualquer informação de fonte primária que ainda não foram analisados e não receberam um tratamento analítico ou que ainda podem ser reelaborados.

\section{CONSIDERAÇÕES FINAIS}

Este trabalho teve por objetivo, identificar as oportunidades que a Construção civil trás ao profissional atuário que segundo alguns estudos pesquisados e autores, o profissional tem estado em seu melhor momento e consequentemente conquistando seu espaço no mercado de trabalho.

Em primeiro momento, por parte dos elaboradores foi grande e desafiador pesquisar sobre um assunto jamais visto ou ouvido pelos mesmos, no qual envolveu dedicação e atenção para melhor desempenho.

Foi esclarecida a suma importância do profissional Atuário, onde sua atuação é essencial para a maior segurança dos que estão envolvidos na Construção civil. Pudemos analisar que na realidade o Profissional Atuário é o verdadeiro Engenheiro de Seguros, pois ele quem calcula toda a probabilidade e riscos de acordo com as estatísticas, no caso da Construção civil, englobando os trabalhadores, equipamentos, tamanhos e conclusão da obra. Nada mais é que um profissional 
multidisciplinar porque precisa ter conhecimento em Direito, Economia, Matemática, Estatística, Engenharia, Informática.

Vimos também que o Atuário pode atuar em diversas áreas, como em Órgãos de fiscalização, Instituições financeiras, Seguradoras, Resseguradoras, Fundo de pensões, Previdência social e entre outras. E deve estar sempre atento as necessidades da sociedade.

Concluímos então que Copa do Mundo 2014 sem duvida será um marco para a expansão desse profissional, a demanda por seu serviço e inúmeras construções sendo realizadas como Estádios, hotéis, comércios, ampliações de rodovias e outras, onde envolve uma série de trabalhadores e equipamentos, faz com que quem o segurado sinta tranquilidade e confiança por saber que os seus estão seguros e cobertos por qualquer risco ou eventualidade.

\section{REFERÊNCIAS}

FACHIN, Odília. Fundamentos de metodologia. 5ạ Ed. São Paulo: Saraiva, 2008.

FIGUEIREDO, Sandra. Contabilidade de seguros. 2aㅡ Ed. São Paulo: Atlas, 2012.

IBA. O Atuário. Disponível em: <http://www.atuarios.org.br/iba/conteudo.aspx?id=2\&sub= 61\&index=1\&mindex=0>. Acesso em: 10 de mai de 2014 .

LAKATOS, Eva Maria. MARCONI, Marina de Andrade. Fundamentos de metodologia científica. 5a Ed. São Paulo: Atlas, 2003.

LIMA, Antonio de et all. Manual de segurança e saúde no trabalho: indústria da construção civil edificações. São Paulo: Sesi, 2008.

SOUZA, Silney de. SEGUROS contabilidade, atuária e auditoria. 1a Ed. São Paulo: Saraiva, 2002.

STANDERSKI, Wlademiro. KRAVEC, Alecseo. Seguros privados e previdência complementar: organização e contabilidade. São Paulo: Livraria Pioneira, 1979. 